\title{
EXPERIMENTAL RESEARCHES AUTOMATION OF SPATIAL OSCILLATIONS OF THE FLOATING OCEAN ENGINEERING SYSTEMS IN THE WAVE BASIN
}

\author{
Olga Ivanova, Veronika Dushko, Anna Rodkina \\ Federal State Educational Institution of Higher Education «Sevastopol State University», \\ Universitetskaya st., 33, Sevastopol, 299053, Russian Federation
}

\begin{abstract}
The presented paper is dedicated to the development of method of experimental researches automation in the wave basin at the investigation of wave impact on ocean engineering system. A scheme for measuring the parameters of mobile objects spatial oscillations, the calibration and verification performing method of the digital devices measuring channels are developed. The dependencies for conversion the data measured in the mobile object coordinate system to stationary data in the base coordinate system are obtained. The characteristics of the angular and translatory motion of semisubmersible platforms physical models when using this equipment system.
\end{abstract}

Keywords: semi-submersible platforms; wave basin; calibration; ocean engineering systems; digital device
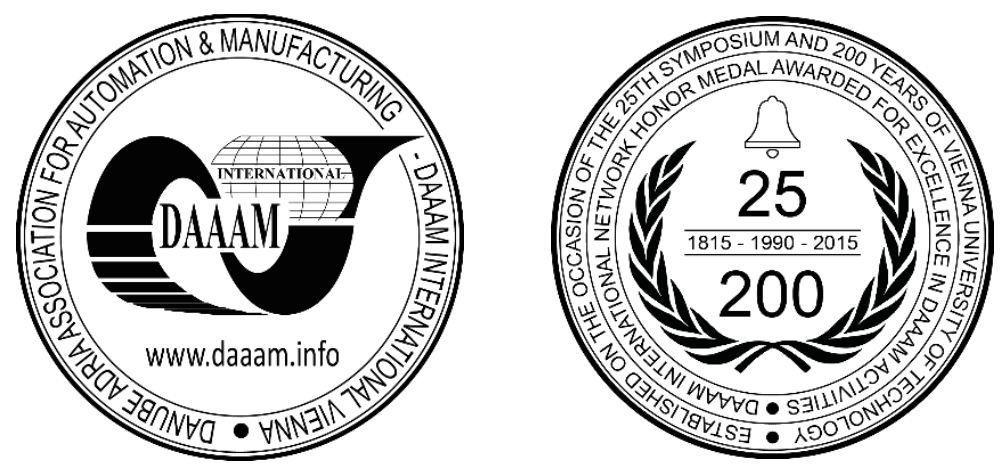

This Publication has to be referred as: Ivanova, O[lga]; Dushko, V[eronika] \& Rodkina, A[nna] (2016). Experimental Researches Automation of Spatial Oscillations of the Floating Ocean Engineering Systems in the Wave Basin, Proceedings of the 26th DAAAM International Symposium, pp.1059-1067, B. Katalinic (Ed.), Published by DAAAM International, ISBN 978-3-902734-07-5, ISSN 1726-9679, Vienna, Austria DOI: $10.2507 / 26$ th.daaam.proceedings. 149 


\section{Problem statement}

Theoretical and experimental studying methods are used at research of wave loads influence on ocean engineering systems. Each of these methods possesses independence and has their own merits and demerits. Generally, theoretical methods in the form of mathematical models allow to describe and explain elements interrelations of the researched system or object in rather wide variables change spectra. However at theoretical models creation inevitably introduction of any restrictions, assumptions, hypotheses, etc. Consequently an assessment problem of the received model reliability to actual process is took place. The experimental inspection of the developed theoretical models is carried out for this purpose. In most cases experimental researches results give an impetus to theoretical generalization of the researched phenomenon. Research works in wave (experimental) basins are carried out in many directions of applied hydrodynamics, shipbuilding, marine technologies.

During development platforms for marine energy resources development, researches in experimental basins are necessary for the solution of many applied problems. Estimates of extreme sea waves impact on the terminals installed in the fixed points; wave loads definition of underwater pipelines in a sea coastal zone [1,2,3], space oscillations studying of floating platforms and stabilization effectiveness of vertical displacements at various design of semi-submersible platforms belong to these problems [4-11].

The automation problem of carrying out the experimental researches of wave impacts on deep-water platforms physical analogues is carried out in the Sevastopol State University experimental wave basin, at various structure of wave disturbances and deepening (draft) of models on the basis of metrological aspects of using the new digital equipment for parameters measurement of platforms models wave and space oscillations. Processing statistical spectral methods of natural experiments results was used for the problem solution of space oscillations spectral characteristics calculation of deep-water platforms under various conditions and estimates of forward and angular oscillations stabilization effects of models depending on their configuration and deepening (draft).

\section{Literature overview}

National and foreign scientists Research works on sea drilling platforms creation and use problems of various types cover the period from 50th years of last century. The works [1-5], [13], [15] are devoted to questions of design engineering, stability and strength of such constructions. Hydrodynamics researches of drilling platforms are described in [6-10], [12], [14], [16-22], [27-28]. Some questions of platform deduction forces calculations on a soil are considered and systematized by [4], underwater vehicles shifts from space trajectory are discussed in [23, 24].

\section{Research course}

Requirements to characteristics of a metering equipment regarding increase in its sensitivity, accuracy, quick action, the automated data processing possibility of measurements increase with the solved tasks complication. The most efficient solution method of the specified tasks is use of the modern microelectronics and the software for processing and interpretation of observed data. One of possible approaches in such equipment creation for ensuring researches in experimental basins was realized at the Sevastopol State University $[1,17,18]$. The digital devices complex was created for automation of carrying out the experimental researches in the experimental basin. Its appointment - the threedimensional (space) oscillations characteristics experimental definition of floating objects at impact of wave disturbances with various parameters, at various physical analogues provisions of rather long axis of the basin and at various deepening of the platforms bearing elements (draft).

Tester nomenclature (Fig. 1):

- the wave basin (1) containing a wave generator (2);

- the working area (3) (where place the tested model (4): the vessel, a platform, the floating crane, etc.), longitudinal, transversal and vertical axes focus arbitrarily along the wave basin;

- $\quad$ the baffle plate (5);

- the meters of the surface spatiotemporal characteristics waves in the form of two wave-recording gauges (6) measuring pressure drops between a receiving opening platform depth of the first and second wave-recording gauges and atmospheric pressure;

- the computer (7) having the first and second entrances;

- the block of wave-recording gauges (8) to which entrance wave-recording gauges exits are connected (poll of measuring channels and a digital conversion). The block of wave-recording gauges is connected to the second entrance of the computer;

- the block of ternary accelerometers and gyroscopes (9) which measuring axes are established along axes of the Cartesian right-hand coordinate system with longitudinal, transversal and vertical axes of the tested model, an exit of this block is connected to the first entrance of the computer. 


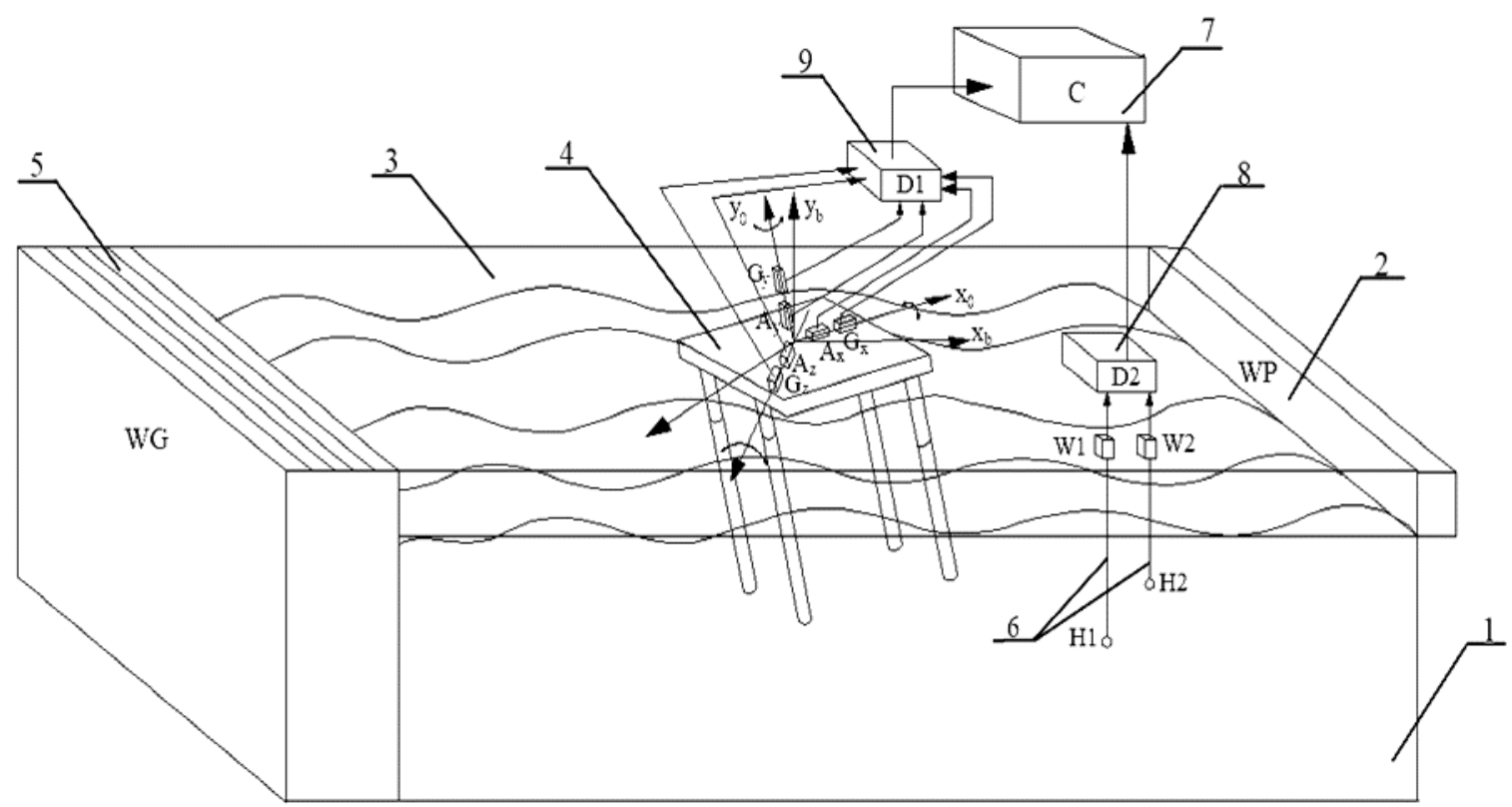

Fig. 1. A complex for space oscillations characteristics measurement of floating objects in the experimental (wave) basin

The way of carrying out tests in the experimental basin of models of floating objects with stretched anchor systems of deduction and the device for its exercise is known RU(11)2389996(13)C1 (51) IPC G01M10/00(2006/01)B63B9/02(2006.01)(12). Patent holder(s): Federal State Unitary Enterprise Central Research Institute of Akkad. A.N. Krylov (RU).

The device for carrying out in the experimental basin of tests of models of floating objects with stretched anchor systems of deduction including the truncated anchor communications each of which contains a flexible communication link with a resilient element by means of which the tested model is attached to foundation of the basin, anchor communications are executed in two-leg sling tensions communication links between which branches the rollers established on model which are attached to its housing mainly on flexible communication are placed, thus the second branches of flexible lines are also equipped with a resilient element, and resilient elements of pair branches of flexible communication links have various rigidity, and other end of branches of the specified flexible lines is attached to foundation of the basin in the corresponding point remote from a point of fixing of their first end [25, 26].

The demerits of the considered technical solutions are:

1. Lack of the wave disturbances given about parameters which have to be measured synchronously with parameters of oscillations of the tested object and efforts in anchor systems of its deduction. Thus, if the wave generator of the experimental basin generates system of waves, always in this or that form there are reflected and reback waves which distort the base wave field. Without actual wave disturbances it is impossible to restore dynamic characteristics of the tested model of floating object and system of its deduction.

This problem is solved by means of two barometric wave-recording gauges (6) (Fig. 1) in the offered work. The Complex for measurement of characteristics of space oscillations of floating objects in the experimental (wave) basin which receiving ends are placed at various depth and at various distance along basin length.

2. In analogue it is also not specified how reliability and long-term stability of indications of component accelerometers and gyroscopes are provided.

The work is alleged for this purpose the compound pendulum, with possibility of serial platform on it the block of ternary accelerometers and gyroscopes so that each of axes of the block coincided with the plane of driving of a pendulum is injected into structure of a complex for measurement of characteristics of space oscillations of floating objects in the experimental (wave) basin. It allows to carry out the regular checkings and metrological certification of the specified meters as parameters of driving of a pendulum are well-known and can be used for the regular checkings and in need of regraduation of measuring channels of accelerometers and gyroscopes.

Work of a complex is carried out as follows. The wave generator executed in the form of pneumatic system or mechanical plasticity excites periodic oscillations with the period Tw (angular frequency $\omega_{w}=2 \pi / T_{w}$ ). These oscillations in the form of the free ground progressive waves extend along the basin. Thus their lengths $\lambda_{\mathrm{w}}$ are defined by a method of successive approximations from a dispersion ratio for the surface waves $\omega^{2}{ }_{w}=g k_{w} \cdot \operatorname{th}\left(k_{w} H\right)$, where $\mathrm{g}=9,81 \mathrm{~m} / \mathrm{c}^{2}$ - free fall acceleration, $k_{w}=2 \pi / \lambda_{w}$ - wave number. Wave-recording gauge $W_{1}, W_{2}$ measure differences of pressure between the atmosphere and an aqueous medium at a depth of platform of receivers $H_{1}, H_{2}$. Amplitude of 
swell $a_{w}$ is calculated on the basis of difference of pressure, the recorded each wave-recording gauge on the relation for hydrodynamics of waves surface $[21,26,27]$ :

$$
a_{w}=\frac{p_{w} \operatorname{chkH}}{\rho g \operatorname{chk}(y+H)}
$$

where $p_{w}$ is the pressure acceleration amplitude, $\rho$ is the water density, $\mathrm{y}$ is the vertical coordinate counted from a surface towards the bottom with the negative sign. Static processing of indications of wave-recording gauge allows to determine the frequency of wave disturbances, phase shift $\gamma$ between oscillations on a base frequency (maximum frequency) and amplitude of wave oscillations at the given distance from a surface of the bottom. In phase displacement size $\gamma$ between wave-recording gauges along length of the basin the actual wavelength is determined by a ratio $\lambda_{r}=2 \pi L_{w} / \gamma\left(L_{w}\right.$ is the distance between wave-recording gauges along basin length). For the linear waves relation of amplitudes $p_{w}$ at each depth of platform of receivers $\mathrm{H}_{1}$ and $\mathrm{H}_{2}$ is equal:

$$
\frac{a_{w}\left(y_{1}\right)}{a_{w}\left(y_{2}\right)}=\frac{p_{w}\left(y_{1}\right) \operatorname{ch} k_{w} H}{\rho g c h k_{w}\left(y_{1}+H\right)} \times \frac{\rho g \operatorname{ch} k_{w}\left(y_{2}+H\right)}{p_{w}\left(y_{2}\right) \operatorname{ch} k_{w} H}=\frac{p_{w}\left(y_{1}\right) \operatorname{ch} k_{w}\left(y_{2}+H\right)}{p_{w}\left(y_{2}\right) \operatorname{ch} k_{w}\left(y_{1}+H\right)}
$$

In case of emergence in the basin multiply of back waves this ratio is broken, then make calculation of parameters of these back waves according to indications of wave-recording gauges carried on the specified distances along the basin and on depth. Generally there is a partial reflection of a wave from a baffle plate and in this case as shows the analysis, amplitude of a straight line and back wave are equal respectively:

$$
a_{n}=0.5 a_{w}\left(1+\frac{\operatorname{tg} \gamma}{\operatorname{tg} k_{w} L_{w}}\right), a_{0}=0.5 a_{w}\left(1-\frac{\operatorname{tg} \gamma}{\operatorname{tg} k_{w} L_{w}}\right)
$$

If $\Delta \varphi=0, a_{n}=a_{0}=0.5 a_{w}$, that corresponds to the total reflection of a wave at $\gamma=k_{w} L_{w}, a_{n}=a_{w}, a_{0}=0$, i.e. the back wave is absent. Sizes $a_{w}$ and $\gamma$ define as a result of realization of a spectral analysis of signals of the first and second wave-recording gauges.

The surface waves, which parameters are defined by means of wave-recording gauges system, influence floating object and cause its space oscillations, i.e. rotational and headways of rather longitudinal $o x_{o}$, transversal $o z_{o}$ and conditionalvertical $o y_{o}$ axes of the tested model. Axes of the block of ternary accelerometers and gyroscopes establish along the specified axes $o x_{o}, o y_{o}, o z_{o}$. Also some fixed (basic) coordinate system, which measuring axes are considered $o x_{b}$ and $o z_{b}$ lie in the plane of the true horizon, and an axis $o y_{b}$ it is directed upright up and forms with this plane a corner is equal $90^{\circ}$. As such system there can be the arbitrariest fixed coordinate system, bound to horizontal axes $o x_{b}, o z_{b}$ and vertical axis $o y_{b}$, for example, coordinate system, bound to the wave basin. For communication of coordinate system $o x_{b}, o z_{b}, o y_{b}$ and $o x_{o}, o z_{o}, o y_{o}$ Euler-Krylov's corners are used. Course corner $\psi$ (in certain cases it is called a roving corner) it is counted in the horizontal plane between the axis $o x_{b}$ and horizontal projection of the axis $o x_{o}$; hull angle $\theta$ (tangauge), characterizing a deviation of a long axis of the relative mobile object from the horizontal plane and angle of heel $\varphi$, characterizing the $o z_{o}$ axis deviation from the horizontal plane at rotation of object of rather long axis. These corners are defined by means of a three-axial gyroscope that provides recalculation of the accelerations measured in a relative coordinate system of coordinates in accelerations in the fixed (basic) coordinate system and, therefore, in components of space oscillations of the relative mobile object $[9,12,16]$.

Projections of unit vectors of a coordinate system $o x_{o}, o y_{o}, o z_{o}$ on an axis of a basic (fixed) coordinate system $o x_{v} y_{v} z_{v}$ are equal to direction cosines of corners between axes $o x_{o}, o y_{o}, o z_{o}$ and $o x_{b}, o y_{b}, o z_{b}$. These direction cosines are presented in the table 1.

\begin{tabular}{llll}
\hline$a_{i j}$ & $o x_{o}$ & $o y_{o}$ & $o z_{o}$ \\
\hline \multirow{2}{*}{$o x_{b}$} & \multirow{2}{*}{$a_{11}=\cos \psi \cdot \cos \theta$} & $\begin{array}{l}a_{12}=\sin \psi \cdot \sin \varphi- \\
\cos \psi \cdot \cos \varphi \cdot \sin \theta\end{array}$ & $\begin{array}{l}a_{13}=\sin \psi \cdot \cos \varphi+ \\
\cos \psi \cdot \sin \varphi \cdot \sin \theta\end{array}$ \\
\hline$o y_{b}$ & $a_{21}=\sin \theta$ & $a_{22}=\cos \varphi \cdot \cos \theta$ & $a_{23}=-\sin \varphi \cdot \cos \theta$ \\
\hline \multirow{2}{*}{$o z_{b}$} & \multirow{2}{*}{$a_{31}=-\sin \psi \cdot \cos \theta$} & $\begin{array}{l}a_{32}=\cos \psi \cdot \sin \varphi+ \\
\text { sin } \psi \cdot \cos \varphi \cdot \sin \theta\end{array}$ & $a_{33}=\cos \psi \cdot \cos \varphi-$ \\
\end{tabular}

Table 1. Direction cosines 


$$
\begin{aligned}
& x_{b}=x_{o}+(\varphi \psi-\theta) y_{o}+(\psi+\varphi \theta) z_{o}, y_{b}=\theta x_{o}+y_{o}-\varphi z_{o} \\
& z_{b}=-\psi x_{o}+(\varphi+\psi \theta) y_{o}+(1-\varphi \theta \psi) z_{o}
\end{aligned}
$$

As amplitudes of angular oscillations are small, works of angular data can be excluded, as, for example, $\varphi \psi<<\theta$ etc. Thus the ratio (4) becomes simpler:

$$
\begin{aligned}
& x_{b}=x_{o}-\theta y_{o}+\psi z_{o}, \frac{d x_{b}}{d t}=\frac{d x_{o}}{d t}-y_{o} \frac{d \theta}{d t}-\theta \frac{d y_{o}}{d t}+z_{o} \frac{d \psi}{d t}+\psi \frac{d z_{o}}{d t} \\
& y_{b}=\theta x_{o}+y_{o}-\varphi z_{o}, \frac{d y_{b}}{d t}=\frac{d y_{o}}{d t}+x_{o} \frac{d \theta}{d t}+\theta \frac{d x_{o}}{d t}+z_{o} \frac{d \varphi}{d t}+\varphi \frac{d z_{o}}{d t} \\
& z_{b}=-\psi x_{o}+\varphi y_{o}+z_{o}, \frac{d z_{b}}{d t}=\frac{d z_{o}}{d t}-x_{o} \frac{d \psi}{d t}-\psi \frac{d x_{o}}{d t}+y_{o} \frac{d \varphi}{d t}+\varphi \frac{d y_{o}}{d t}
\end{aligned}
$$

Terms of a set of equations (5) in a right member have significantly the differing values. Products of a look $y_{o}(d \theta / d t)$ and $\theta\left(d y_{o} / d t\right)$ about ten times less than sizes $d x_{b} / d t$ for typical conditions of carrying out measurements in the experimental basin as for steady surface waves their length more than by 10 times exceeds their height. These works also have resultant frequency twice the exceeding frequency of a first harmonic. In this regard, in the conditions of work in the experimental basin and uses of an approximation of small corners with rather high precision it is possible to use ratios:

$$
\begin{aligned}
& x_{b}=x_{o}, y_{b}=y_{o}, z_{b}=z_{o} \\
& \frac{d x_{b}}{d t}=\frac{d x_{o}}{d t}, \frac{d y_{b}}{d t}=\frac{d y_{o}}{d t}, \frac{d z_{b}}{d t}=\frac{d z_{o}}{d t} \\
& \frac{d^{2} x_{b}}{d t^{2}}=\frac{d^{2} x_{o}}{d t^{2}}=A_{x}, \frac{d^{2} y_{b}}{d t^{2}}=\frac{d^{2} y_{o}}{d t^{2}}=A_{y}, \frac{d^{2} z_{b}}{d t^{2}}=\frac{d^{2} z_{o}}{d t^{2}}=A_{z}
\end{aligned}
$$

When determining angular oscillations of the tested model results of immediate measurements of the gyroscopes established on each measuring axis are used. Thus recalculation of indications of gyroscopes of a look $V_{\varphi}=\frac{d \varphi}{d t}=V_{\varphi o} \sin \left(\omega t+\alpha_{\varphi}\right)$ in parameters of angular oscillations it is carried out on a ratio:

$$
\varphi(t)=\frac{V_{\varphi 0}}{\omega} \cos \left(\omega t+\alpha_{\varphi}\right)
$$

Spectral processing of records of these oscillations by three accelerometers and gyroscopes allows to allocate their base frequencies (maxima oscillation spectra of frequency) which coincide with frequencies of the wave disturbances causing these oscillations.

Thus, platform of measuring axes of the block of ternary accelerometers and gyroscopes along axes of the Cartesian right-hand coordinate system coinciding with longitudinal transversal and it is conditional - vertical axes of the tested model at connection of an exit of this block to the first entrance of the computer, to which second entrance connected the wave-recording gauges block, provides completeness of information on impact of waves on the tested model thanks to synchronous measurements of parameters of a straight line and reflected waves in a coordinate system, bound to the basin, and also the forward and rotational oscillations of the tested model measured in the same coordinate system [19].

In the real work the scheme of parameters measurements realization of space oscillations of the relative mobile objects, a calibration realization technique and check of measuring channels of the digital device when using of the created express adaptation in the form of a compound pendulum which frequency of eigentones is close to the frequency of the free waves in the experimental basin of the Sevastopol State University is developed. Data processing of laboratory experiments when using median filters is executed. The analysis of the received amplitude-frequency characteristic of median filters for a discernment and correction of failures of narrow-band signals, showed possibility of their effective use under a condition if the reference frequency period exceeds base of the filter (number of the used counting increased by a discretization of measurements) in 2,5... 3 times. As a result of the executed laboratory experimental researches of physical analogues of semi-submersible platforms for deep-water drilling, the received dependences of amplitude of vertical and angular oscillations of a platform at various deepening of the stabilizing columns, allow to define rational deepening (draft) of platforms at influence of extreme surface waves in the Black Sea. The effect of platforms oscillations stabilization for deep-water drilling depending on a configuration of platforms and deepenings (draft) of their load-bearing mobiles is found. Parameters horizontal and heave of physical analogues of deep-water SPAR and TLP platforms were 
investigated at various duties of a wave generator and at the different provision of a platform of wave disturbances relatively extended in the experienced basin $[10,20]$.

For researches of wave dynamics of platforms it is necessary to define characteristic periods of their oscillations. These parameters were determined by filing of the free oscillations of model of a platform on quiet water. Separately the periods of characteristic oscillations were determined by a list and down. For this purpose indications of accelerometers which axes coincided with a long axis of a platform (ox) and with conditionally vertical axis (oy) were used. The normalized spectra which maxima correspond to the periods of oscillations are equal 1,2 with are received, and these periods coincide for angular and heave of model of a platform.

On the fig. $2 \mathrm{a}$ and $2 \mathrm{~b}$ lower spectra of horizontal and vertical accelerations of the TLP model at various deepening (draft) are presented. In terms of the actual sizes of a platform these drafts are equal 86, 81, 76 and $71 \mathrm{~m}$. Measurements were taken at the wave generator mode that provides the period of wave disturbances - 0,61 with at a wavelength - 0,58 $\mathrm{m}$ and its height $-2 \mathrm{~cm}$. The long axis of a platform coincides with the main direction of propagation of waves

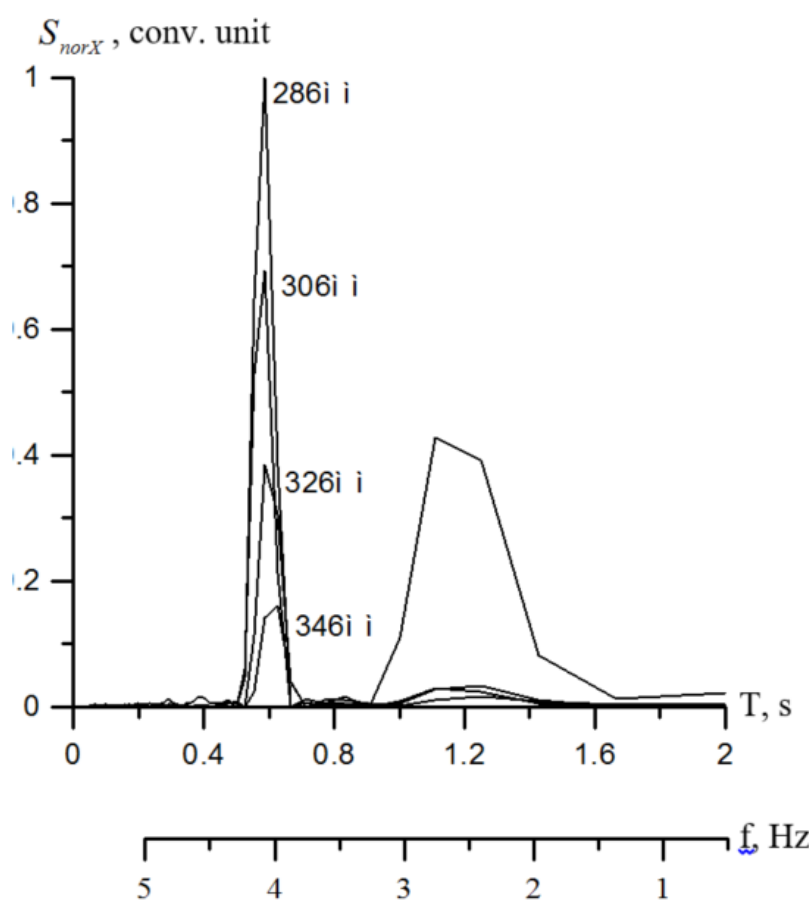

Fig. 2. (a) Spectra of horizontal accelerations of the TLP model at various deepening (draft)

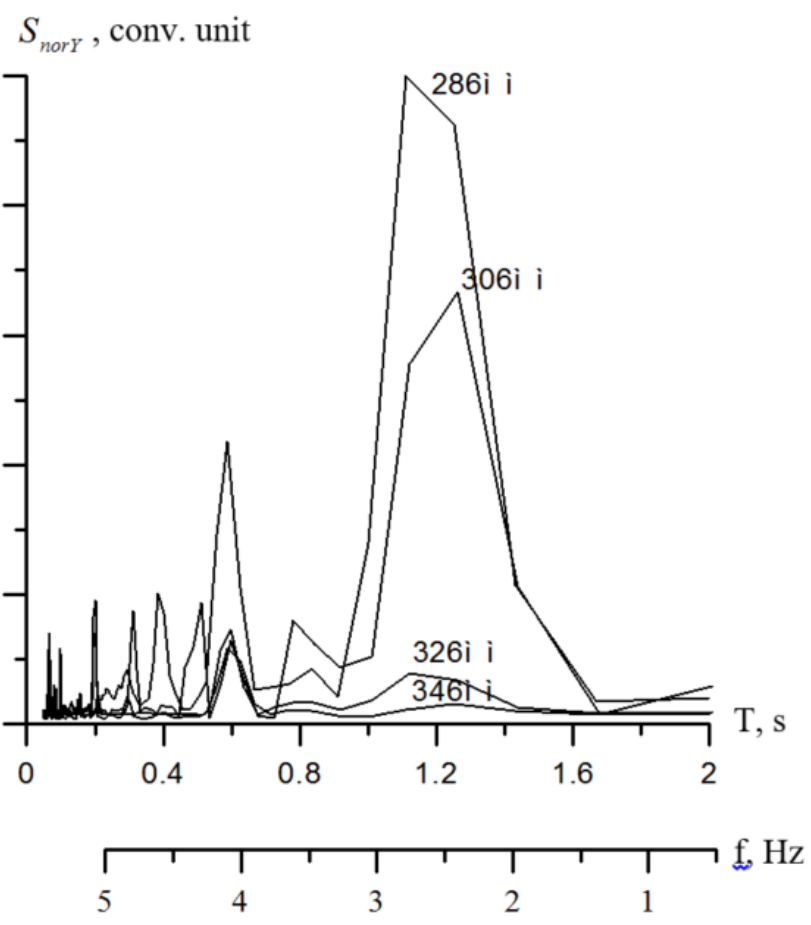

Fig. 2. (b) Spectra of vertical accelerations of the TLP model at various deepening (draft

On spectra of horizontal accelerations the effect of decrease of peak of a range on a base frequency of oscillations ( 0,6 clearly was shown c) at increase in a draft of a platform. Considerably accelerations, smaller in size, on the doubled period are caused probably by nonlinearity of hydrodynamic system a platform - an aqueous medium taking into account the mass of model and the associated mass of water. Spectra of these low-frequency oscillations there are much less than spectra of accelerations on a base frequency (except for a draft of $71 \mathrm{~m}$ ), but even at this draft amplitude of horizontal shifts of these low-frequency oscillations will be four times less than similar size on the period 0,6 with, i.e. will make about $10 \%$ of the maximal horizontal shifts on a fundamental period of oscillations [17-19].

On spectra of heave the decrease effect of accelerations at increase in a draft of a platform was shown on the period 1,2s. On a fundamental period of indignations this effect is also shown rather clearly. Besides, oscillations on combination frequencies with doubled, trebled and higher frequencies of rather base frequency of wave disturbances were considerably shown.

For the specified experimental conditions amplitudes of shifts of model of a platform on horizontal and vertical axes were calculated. The following ratios for amplitudes of accelerations on the corresponding axes are used $A_{X}=0,6472 \sigma_{n x}, A_{Y}=0,6303 \sigma_{n y}$. Amplitudes $A_{X P}$ and $A_{Y P}$ forward oscillations on axes ox,oy are equal respectively $A_{X P}=A_{X} / \omega^{2}, A_{Y P}=A_{Y} / \omega^{2}$, where $\omega$ - the prevailing oscillation frequency. Dependences of these sizes are given in fig. 3. It is visible that at change of a draft in the specified limits amplitude horizontal and heave decreases approximately twice. 


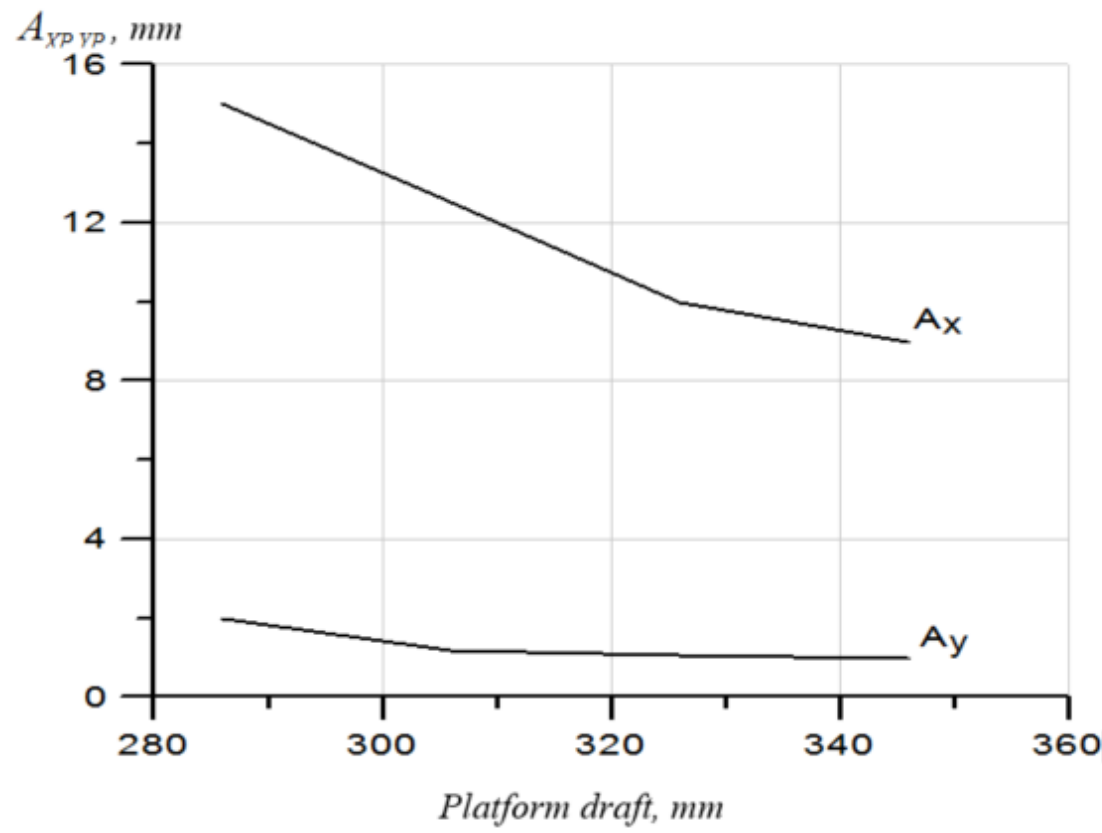

Fig.3. Amplitudes of the horizontal ( ) and the vertical ( ) shifts of model under the conditions of carrying out measurements stated above

The physical analogue of the SPAR platform also was researches object of oscillations stabilization effect at various deepening (draft) and at various operations of a wave generator (that is at various parameters of wave disturbances). The research technique did not differ from similar researches of the TLP platform. The platform kept in a point by means of four anchors which fastening was in an upper of a cylindrical construction. Similar researches were executed at system of deduction of a platform from eight anchors which fastening was in an upper of a load-bearing mobile of a platform.

\section{Conclusion and prospects of further researches}

For experimental researches automation in the experimental basin, the complex of digital equipment for the experimental definition of floating objects three-dimensional (space) oscillations characteristics at impact of wave disturbances with various parameters, at various provisions of physical analogues of rather long axis of the basin and at various deepening of load-bearing mobiles was created.

A scheme for measuring the parameters of mobile objects spatial oscillations, the calibration and verification performing method of the digital devices measuring channels are developed. The technique of carrying out the experimental researches of wave impacts on physical platforms analogues for deep-water drilling in the experimental (wave) basin which unlike the known provides data on parameters of the straight lines and back waves operating on the tested model and its reactions to these waves that allows to receive the complete information on platform dynamics at various parameters of wave influences gained further development.

The offered technique of carrying out experiments on physical analogues in the experimental basin for the obtained experimental data verification, when using of the created complex of digital devices, is applied to a semisubmersible drilling platform of regular type. The obtained experimental data are compared with numerical model. The analysis of the experimental data obtained when using two digital devices types is made, the received results error and also a new complex of digital devices advantages is defined. Comparing the results received when using of the considered measuring systems it was noted that using of the mobile objects space oscillations meter, containing a ternary gyroscope and accelerometers, significantly expands the frequenciest range of the researched oscillations up to the periods of 0,02 s. The new complex of the digital equipment in the main principal specifications surpasses existing by 10 times on dynamic range, it works in the independent mode that excludes need of cable communication with the external computer. The obtained experimental data during the using of the new digital equipment and a technique of carrying out experiments in the experimental basin were compared with the results of the experimental researches and numerical model presented in Moreva I.N. PhD work [11], which relative deviation is in limits 5...7\%. Thus, reliability of the executed experimental researches in the experimental basin at impact on platforms of the surface waves with various parameters is confirmed by data of numerical model.

Complex researches in laboratory and bench conditions of deep-water platforms physical analogues hydrodynamics and researches of stabilization parameters depending on a platform configuration and deepening (draft) of their load-bearing constructions are carried out for the purpose of verification and specification of the developed hydrodynamic models of such platforms. 


\section{References}

[1] Alisejchik A.A., Galahov I.N., Litonov O.E. Floating drilling platforms. Structure and strength. - L.: Shipbuilding, 1981. - 224 p. Alisejchik A.A., Galahov I.N., Litonov O.E. Plavuchie burovye platformy. Konstrukciya i prochnost'. - L.: Sudostroenie, 1981. - 224 s.

[2] Dushko V.R., Kushnir V.M. Characteristics of surface waves and currents impact on the submersible drilling platforms // SevSTU reporter. - Sevastopol, 2006. - Issue 75. - pp. 65 - 73. Dushko V.R., Kushnir V.M. Harakteristiki vozdejstviya poverhnostnyh voln i techenij na pogruzhnuyu burovuyu ustanovku // Vestnik SevGTU. - Sevastopol': SevGTU, 2006. - Vyp. 75. - S. $65-73$.

[3] Dushko V.R. Stability of sea drilling platforms on soft and moving grounds. PhD work. - Nikolaev, 2007. - 113 p. Dushko V.R. Ustojchivost' morskih burovyh platform na myagkih i podvizhnyh gruntah. Dissertaciya kand. tekhnich. nauk. NUK, Nikolaev, 2007. - $113 \mathrm{~s}$.

[4] Douson T. Offshore structural engineering. L.: Shipbuilding, 1986. - 286 p. Douson T. Proektirovanie sooruzhenij morskogo shel'fa. - L.: Sudostroenie, 1986. - 286 s.

[5] Shostak V.P. The effectiveness of offshore engineering. - Kiev, 2002. - 319 p. Shostak V.P. Effektivnost' tekhniki osvoeniya okeana. - K.: «Naukova dumka», 2002. - $319 \mathrm{~s}$.

[6] Barshtejn M.F., Zubkov A.N., Maslov B.E. Experimental study of the oil-field structure fluctuations at irregular waves / Tr. CNIISK im. Kucherenko, Issue 34. - Moscow, 1974. Barshtejn M.F., Zubkov A.N., Maslov B.E. Eksperimental'noe izuchenie kolebanij neftepromyslovyh sooruzhenij pri neregulyarnom volnenii/Tr. CNIISK im. Kucherenko, vyp. 34. - M.: Strojizdat, 1974.

[7] Lappo D.D., Strekalov S.S., Zav'yalov V.K. Pressures and impact of wind waves on the waterworks. - Leningrad, 1990. - 432 p. Lappo D.D., Strekalov S.S., Zav'yalov V.K. Nagruzki i vozdejstvie vetrovyh voln na gidrotekhnicheskie sooruzhe-niya. Izd. VNII gidrotekhniki im. B.E.Vedeneeva. Leningrad.1990. - 432 s.

[8] Litonov O.E. Evaluation of extreme loads on the jack-up drilling rig in the joint action of waves and wind. - L.: Shipbuilding, 1977. - pp. 14-15. Litonov O.E. Ocenka ekstremal'nyh nagruzok na samopod"emnye burovye ustanovki pri sovmestnom dejstvii volneniya i vetra. - L.: Sudostroenie, 1977. - S.14-15.

[9] Halfin I.Sh. The impact of waves on offshore oil and gas facilities. - SPb.: Nedra, 1990. - 310 p. Halfin I.Sh. Vozdejstvie voln na morskie neftegazopromyslovye sooruzheniya. - SPb.: Nedra, 1990. - $310 \mathrm{~s}$.

[10] Moreva I.N., Ivanova O.A., Rodkina A.V. Analysis of TLP Marine Semi-Submersible Platform Model Behavior on a Seaway. - Proceedings of Sevastopol National University of Nuclear Energy and Industry. Sevastopol, 2013. Issue №3 (47). - pp. 124-129. Moreva I.N. Analiz povedeniya modeli morskoj polupogruzhnoj platformy tipa TLP na volnenii // I.N. Moreva, O.A. Ivanova, A.V. Rod'kina // SNUYAEiP Sb. nauk. pr. - 2013. - Vyp. №3(47) - S. 124129.

[11] Moreva I.M. Hydrodynamics of the spatial oscillation of the semisubmersible platform under storm condition. PhD work. - Odesa. - 2009. -123 p. Moreva I.M. Gidrodinamika prostorovih kolivan' napivzanuryuvanoï platformi u shtormovih umovah/ I.M. Moreva - Disertaciya kand. tekhnich. nauk: 05.08.01: zashchishchena 22.04.09/ ONMU, Odesa. - 2009. -123 s.

[12] Cheong Hin-Fatt, Shenkoz J.N., Subbiah K. Wave Forces on Submarine Pipelines near a Plane Boundary// Ocean Eng. - 1987. - 14, № 3. - pp. $181-200$.

[13] Nesin Danilo Y. Numerical Model of the Large Carrying Capacity Crane Ship with the Fully Revolving Topside / Danilo Y. Nesin, Veronica R. Dushko // Annals of DAAAM for 2014, Issue 25, No.1, ISSN 2304-1382 \& Proceedings of the 25th DAAAM International Symposium on Intelligent Manufacturing and Automation, Issue 100, ISSN 1877-7058, Edited by Branko Katalinic, ELSEVIER, 2015. - pp. 1082-1091.

[14] Moreva I.N., Ivanova O.A., Dushko V.R. Investigations of the drilling platform dynamics in the experimental basin with the help of digital devices. - Environmental Management Systems. Issue №15. - pp. 296-301. Moreva I.N. Issledovanie dinamiki burovoj platformy v opytovom bassejne s pomoshch'yu cifrovyh ustrojstv [Tekst] / I.N. Moreva, O.A. Ivanova, V.R. Dushko // Sistemy kontrolya okruzhayushchej sredy. Sb. nauch. tr. MGI NAN Ukrainy. - 2011. - Vyp. №15. - S. 296-301.

[15] Franchuk V.G., Chuprun V.P., Yaremijchuk Ya.S., Shvachenko I.I., Strunevich O.V. Analysis of the current status of marine technological complexes. - Oil and gas. № 9. - 2009. - pp. 22-30. Franchuk V.G. Analiz sovremennogo sostoyaniya morskih tekhnologicheskih kompleksov / V.G. Franchuk, V.P. Chuprun, Ya.S. Yaremijchuk, I.I. Shvachenko, O.V. Strunevich // «Heft' i gaz». - № 9. - 2009. - S. 22-30.

[16] Mazurkiewicz, B. Offshore Platforms and Pipelines [Text] / B. Mazurkiewicz - Transtech publications, 1987. - 385 p.

[17] Kushnir V.M., Dushko V.R., Moreva I.N., Ivanova O.A. Hydrodynamics deepwater platforms to conditions of the Black Sea: Manuscript. - Sevastopol, 2012. - 233 p. Kushnir V.M. Gidrodinamika glubokovodnyh platform dlya uslovij Chernogo morya: monografiya [Tekst] / V.M. Kushnir, V.R. Dushko, I.N. Moreva, O.A. Ivanova // Izdatel'stvo SevNTU, 2012. - $233 \mathrm{~s}$.

[18] Kushnir V.M., Ivanova O.A., Moreva I.N., Dushko V.R. Features of the dynamics of deep drilling platforms for the central part of the Black Sea. - Proceedings of Sevastopol National University of Nuclear Energy and Industry. Sevastopol, 2010. Issue №4 (36). - pp. 152-158. Kushnir V.M. Osobennosti dinamiki glubokovodnyh burovyh platform dlya central'noj chasti Chernogo morya [Tekst] / V.M. Kushnir, O.A. Ivanova, I.N. Moreva, V.R. Dushko // Sb. nauch. tr. SNUYAE i P. - 2010. - Vyp. №4 (36). - S. 152-158.

[19] Kushnir V.M. Digital system for ocean engineering systems investigations in wave basins. - ONMU reporter. Issue №34 (1) - pp. 85-102. Kushnir V.M. Cifrovaya sistema dlya issledovanij okeanotekhnicheskih sistem v volnovyh 
bassejnah [Tekst] / V.M. Kushnir, V.R. Dushko, I.N. Moreva, O.A. Ivanova, S.V. Fedorov // Visnik ONMU Sb. nauk. pr. - 2012. - Vyp. №34 (1) - S. 85-102.

[20] Srinivasan, Nagan. Tension base TLP can support development in $4000 \mathrm{ft}$ depths [Text] / Nagan Srinivasan // Offshore. - March 1995. - P. 48, 50, 65.

[21] Demirbilek, Z.Ed. Tension Leg Platform: a state of the art review [Text] / Z. Demirbilek. - New York: American Society of Civil Engineers, 1989. - 70 p.

[22] Vugts I.J.H. The analysis of floating structures in waves / I.J.H. Vugts // Technology International. - Brighton, 1972. - pp. 212-219.

[23] Filaretov V.F. Method of Synthesis of Automatic Correction Systems of Underwater Vehicles Linear Displacements / V.F. Filaretov, A.Yu. Konoplin, N.Yu. Konoplin // Annals of DAAAM for 2014, Issue 25, No.1, ISSN 2304-1382 \& Proceedings of the 25th DAAAM International Symposium on Intelligent Manufacturing and Automation, Issue 100, ISSN 1877-7058, Edited by Branko Katalinic, ELSEVIER, 2015. - pp. 1434-1440.

[24] Filaretov V.F. System of Automatically Correction of Program Trajectory of Motion of Multilink Manipulator Installed on Underwater Vehicle / V.F. Filaretov, A.Yu. Konoplin // Annals of DAAAM for 2014, Issue 25, No.1, ISSN 2304-1382 \& Proceedings of the 25th DAAAM International Symposium on Intelligent Manufacturing and Automation, Issue 100, ISSN 1877-7058, Edited by Branko Katalinic, ELSEVIER, 2015. - pp. 1441-1449.

[25] Patent R.F. №2011169 G01 C21/00, 15.04.94. B.№7.

[26] Patent R.F. №239996 G01 M10/00 (2006/01).

[27] Ng, C.Y.; Kurian, V.J.; Liew, M.S., "Experimental investigation for the responses of semi-submersible platform subjected to bidirectional waves," in National Postgraduate Conference (NPC), 2011 , vol., no., pp.1-5, 19-20 Sept. 2011.

[28] Abbas, M.Y.; Kurian, V.J.; Harahap, I.S.; Abu Bakar, N., "Numerical study on the dynamic response of a semisubmersible platform with experimental validation," in Science and Social Research (CSSR), 2010 International Conference on , vol., no., pp.282-287, 5-7 Dec. 2010. 